\title{
Anticancer Effects of Lingonberry and Bilberry on Digestive Tract Cancers
}

\author{
Tuulia Onali ${ }^{1,2,3}$, Anne Kivimäki ${ }^{1,2}$, Matti Mauramo ${ }^{4}$ (), Tuula Salo ${ }^{1,3,5,6}$ and Riitta Korpela ${ }^{2,7, *}$ \\ 1 Department of Oral and Maxillofacial Diseases, Faculty of Medicine, University of Helsinki, \\ 00014 Helsinki, Finland; tuulia.onali@helsinki.fi (T.O.); anne.kivimaki@helsinki.fi (A.K.); \\ tuula.salo@helsinki.fi (T.S.) \\ 2 Medical Nutrition Physiology, Department of Pharmacology, Faculty of Medicine, University of Helsinki, \\ 00014 Helsinki, Finland \\ 3 Translational Immunology Research Program (TRIMM), University of Helsinki, 00014 Helsinki, Finland \\ 4 Department of Pathology, Faculty of Medicine, University of Helsinki and Helsinki University Hospital, \\ 00014 Helsinki, Finland; matti.mauramo@helsinki.fi \\ 5 Cancer and Translational Medicine Research Unit, University of Oulu, 90014 Oulu, Finland \\ 6 Medical Research Centre, Oulu University Hospital, 90014 Oulu, Finland \\ 7 Human Microbiome Research Program, University of Helsinki, 00014 Helsinki, Finland \\ * Correspondence: riitta.korpela@helsinki.fi
}

Citation: Onali, T.; Kivimäki, A.; Mauramo, M.; Salo, T.; Korpela, R. Anticancer Effects of Lingonberry and Bilberry on Digestive Tract Cancers. Antioxidants 2021, 10, 850. https://doi.org/10.3390/ antiox10060850

Academic Editor: Mario Allegra

Received: 12 April 2021

Accepted: 21 May 2021

Published: 26 May 2021

Publisher's Note: MDPI stays neutral with regard to jurisdictional claims in published maps and institutional affiliations.

Copyright: (c) 2021 by the authors. Licensee MDPI, Basel, Switzerland. This article is an open access article distributed under the terms and conditions of the Creative Commons Attribution (CC BY) license (https:/ / creativecommons.org/licenses/by/ $4.0 /)$.

\begin{abstract}
Wild berries are part of traditional Nordic diets and are a rich source of phytochemicals, such as polyphenols. Various berry treatments have shown to interfere with cancer progression in vitro and in vivo. Here, we systematically reviewed the anticancer effects of two Nordic wild berries of the Vaccinium genus, lingonberry (Vaccinium vitis-idaea) and bilberry (Vaccinium myrtillus), on digestive tract cancers. The review was conducted according to the PRISMA 2020 guidelines. Searches included four databases: PubMed, Scopus, Web of Science, and CAB abstracts. Publications not written in English, case-reports, reviews, and conference abstracts were excluded. Moreover, studies with only indirect markers of cancer risk or studies with single compounds not derived from lingonberry or bilberry were not included. Meta-analysis was not performed. The majority $(21 / 26)$ of studies investigated bilberry and colorectal cancer. Experimental studies on colorectal cancer indicated that bilberry inhibited intestinal tumor formation and cancer cell growth. One uncontrolled pilot human study supported the inhibitory potential of bilberry on colorectal cancer cell proliferation. Data from all 10 lingonberry studies suggests potent inhibition of cancer cell growth and tumor formation. In conclusion, in vitro and animal models support the antiproliferative and antitumor effects of various bilberry and lingonberry preparations on digestive tract cancers.
\end{abstract}

Keywords: lingonberry; bilberry; colorectal cancer; oral cancer; proliferation; invasion; migration; tumorigenesis; phytochemical; polyphenol; anthocyanin; proanthocyanidin

\section{Introduction}

Diets rich in non-starchy vegetables and fruits reduce the risk of many non-communicable diseases, such as digestive tract cancers [1,2]. Plant-based diets provide vitamins, minerals, and dietary fiber, but also various plant metabolites generally called phytochemicals, such as polyphenols and phenolic acids. These are food constituents not regarded as essential but recently shown to have health benefits, especially in the prevention and management of chronic diseases, including cancer [3,4]. Dietary plants contain thousands of different phytochemicals, which produce a variety of metabolites in the human digestive system [4]. Polyphenols can modulate carcinogenic processes, such as cellular proliferation, differentiation, apoptosis, inflammation, angiogenesis, and metastasis [3,5]. The anthocyanins especially raise interest as promising candidates for cancer prevention and drug development, yet evidence from human trials is still lacking [6]. 
Bioavailability of dietary polyphenols and other phytochemicals has been considered low, since only small concentrations can generally be found in systemic circulation following ingestion [4]. However, since dietary phytochemicals are extensively modified by host and microbial enzymes [4,7], post-prandial serum concentration of a certain phytochemical is not directly indicative of its biological impact, especially on the digestive tract tissues. Some phytochemicals are absorbed intact or as degradation products from the upper digestive tract, whereas others travel to lower digestive tract and produce absorbable metabolites hours later [4,7]. Absorbed compounds are further metabolized in the epithelial cells of the gastrointestinal wall and liver, after which these metabolites can continue to systemic circulation or return to the gut lumen due to enterohepatic circulation. Post-prandial serum concentration of a degradation product can be hundred-fold compared to that of the original phytochemical ingested [8]. In addition, phenolic compounds can accumulate into tissues over time $[9,10]$.

Whole berry extracts and berry polyphenols purified from extracts, reduce tumor cell proliferation in vitro, and reduce tumor formation and growth in murine models [11]. Berry polyphenols not only exerts antioxidant potential but also inhibits inflammation, invasion, mutagenesis, and induces apoptosis in malignant cells. Some polyphenols inhibit glucose transport [12] and may therefore inhibit vigorously proliferating tumor cells that rely on high influx and metabolism of glucose [13].

Lingonberry (Vaccinium vitis-idaea) and bilberry (Vaccinium myrtillus) are common dietary fruits and one of the richest dietary sources of polyphenols, especially anthocyanins, in Finnish diets $[14,15]$. These berries belong to the genus Vaccinium but differ in their biochemical composition, with the proportion of anthocyanins being considerably high in bilberry and that of proanthocyanidins in lingonberry [16]. The objective of this systematic review was to collect current English-written scientific research on the anticancer effects of lingonberry and bilberry on digestive tract cancers. These effects of berries on digestive tract cancers have been extensively reviewed by Bishayee et al. [11], but to our knowledge, no systematic review encompassing anticancer effects of lingonberry or bilberry has been published to date.

\section{Materials and Methods}

Protocol of this review was registered and is available in PROSPERO (PROSPERO 2020CRD42020181924). Eligible studies included original research papers with the following components: 1 . Lingonberry or bilberry treatment (fermented or not fermented whole berry or berry juice, whole berry extracts, anthocyanin-rich extracts, and other fractions of extracts derived from bilberry or lingonberry); 2 . digestive tract human cancer cell line, animal model, or human patients; 3 . treatment tested on a direct cancer-relevant endpoint, including the number and size of tumors or pre-cancerous lesions, inhibition of tumor cell proliferation, cytotoxicity, induction of apoptosis, or invasion and migration of tumor cells.

Publications not written in English, case-reports, reviews, and conference abstracts were excluded. Studies with only indirect markers of cancer risk, such as oxidative stress or inflammation, or studies with single compounds not derived from lingonberry or bilberry, were considered outside the scope of this review.

The literature search was carried out by 2 independent reviewers (TO and AK) on 20.4.2020 and updated on 4.3.2021 in four databases: PubMed, Scopus, Web of Science, and CAB abstracts. Search syntax for PubMed, Web of Science, and CAB was as follows: ((lingonberr* OR Vaccinium vitis-idaea OR cowberr* OR mountain cranberr* OR bilberr* OR vaccinium myrtillus OR whortleberr* OR european blueberr*) AND (neoplas* OR metasta* OR invas* OR migrati* OR malignan* OR polyp* OR aberrant crypt foci OR

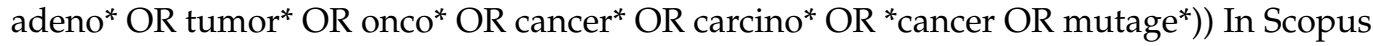
search was divided into two searches; bilberry: TITLE-Abs KEY ((bilberr* OR myrtillus OR whortleberr*) AND (neoplas* OR metasta* OR invas* OR migrati* OR malignan* OR polyp* OR "aberrant crypt foci" OR adeno* OR tumor* OR onco* OR cancer* OR carcino* OR ${ }^{*}$ cancer OR mutage*)) and lingonberry: TITLE-ABS-KEY ((lingonberr* OR vitis-idaea OR 
cowberr* OR "mountain cranberr*") AND (neoplas* OR metasta* OR invas* OR migrati* OR malignan* OR polyp* OR "aberrant crypt foci" OR adeno* OR tumor* OR onco* OR cancer* OR carcino* OR *cancer OR mutage*)).

Duplicates were removed and titles and abstracts were screened by two independent reviewers (TO and AK). Full texts were retrieved for included studies and for papers that did not provide all relevant information in the abstract. A final selection was made in duplicate based on the full text.

Data from each included study was extracted by 2 independent reviewers (TO and AK/MM) using a piloted form. Each study was extracted in duplicate. Disagreements were solved with the 3rd reviewer (AK/MM). Data collected from each study included publication information, authors, cell line/animal model/human population and site of cancer, berry species, berry preparation used for exposure, time of exposure, concentration, end points studied, methods used, controls, number of repeats and replicates (cell studies) or number of studied individuals (animals or human subjects), results, conclusions made by authors, reviewers' evaluation of study quality, and other comments. Due to variable methodology across studies, collected data was considered suitable for qualitative synthesis only. Data was tabulated by cancer type (colorectal or oral cancer) and study type (human study, animal study, or in vitro study).

\section{Results}

The selection process of the systematic search and numbers of included and excluded papers are presented in Figure 1. In total, 43 full text articles were assessed for eligibility, of which 17 [17-33] were excluded based on reasons given in Figure 1. At the end of the selection process, 26 articles were considered eligible for this review. Of these studies, a great majority (25/26) investigated colorectal cancer (CRC); only one cell culture study related to oral cancer was identified, and no publications on other digestive tract cancers with a lingonberry or bilberry treatment were found. Anticancer effects of bilberry preparations on CRC were studied in one human clinical study, 7 animal studies, and 13 cell culture studies. Lingonberry treatment was tested on CRC models in one animal study and 8 cell culture studies. Study characteristics and main results from animal studies related to CRC are presented in Table 1 and from cell culture studies in Table 2.

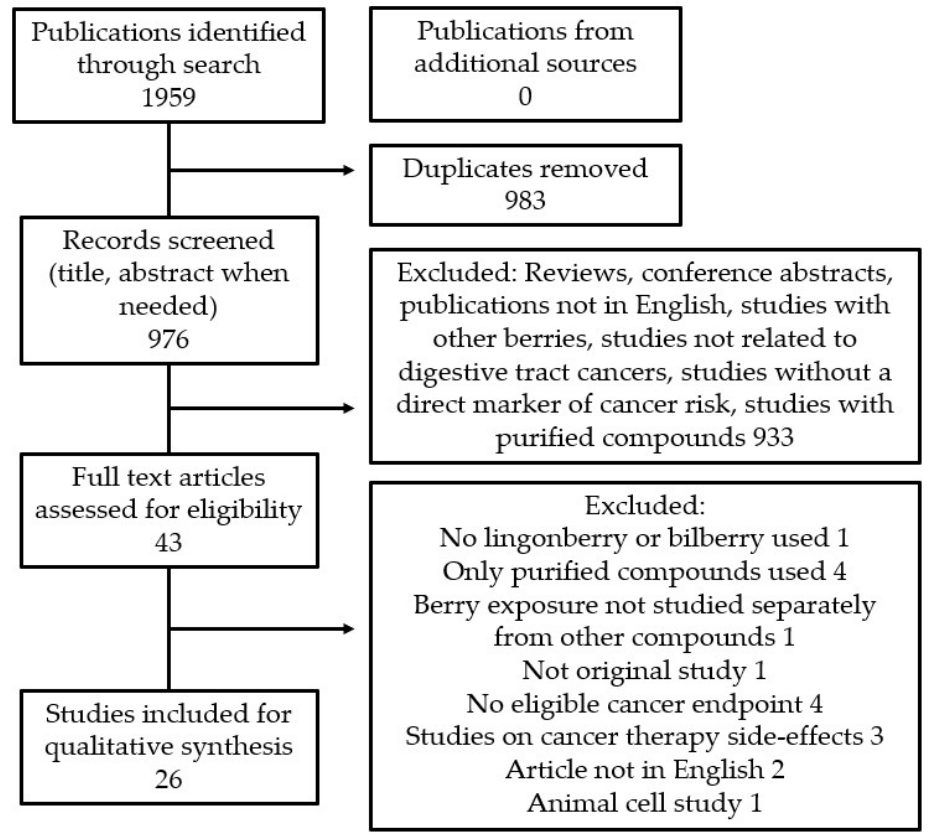

Figure 1. Flow chart of the systematic search and selection process. 


\subsection{Human Study on Colorectal Cancer}

To our knowledge, only one clinical pilot human study on bilberry or lingonberry and any digestive tract cancer has been published to date. Thomasset et al. treated CRC patients with standardized bilberry anthocyanin rich extract, Mirtocyan (Indena S.p.A., Milan, Italy), for seven days before scheduled resection of primary tumor or liver metastasis [10]. Patients were randomized into three groups based on dosage $(1.4 / 2.8 / 5.6 \mathrm{~g} /$ day), but no control group was included. Cellular proliferation and apoptotic index in the tumor tissue were compared to pre-intervention values. After the one-week treatment, tumor cellular proliferation decreased by $7 \%$ and apoptotic index increased from $3.6 \%$ to $5.3 \%$ in all groups combined.

\subsection{Animal Studies on Colorectal Cancer}

Animal experiments on CRC are presented in Table 1. Animal models used were genetic Apc $\mathrm{Min}^{\mathrm{M}+}$ mouse model [9,34,35], toxin-induced carcinogenesis in a rat or mouse [34,35], and a xenograft mouse model with subcutaneously inoculated human adenocarcinoma cells [36,37]. Treatments included freeze-dried lingonberry and bilberry [38], as well as anthocyanin-rich bilberry extracts $[9,34-37,39]$. All these treatments reduced number and/or size of intestinal tumors or pre-malignant lesions. However, bilberry extract alone did not have an effect on subcutaneous tumors in the mouse xenograft, but reduced tumor volume when given in combination with an immune checkpoint inhibitor drug [36,37].

In the rat model of toxin-induced carcinogenesis, bilberry anthocyanin rich extract supplementation significantly reduced the number of total and large colonic aberrant crypt foci (ACF) after 14 weeks of treatment [34]. Proliferation of colonic cells reduced by nearly $50 \%$ and rats fed with this extract had reduced expression of COX-2 mRNA, together with a reduced number of ACF. In a corresponding mouse model study, bilberry anthocyanin rich extract supplementation for 10 weeks significantly reduced the size and number of colon tumors [35]. Interestingly, animals fed with $10 \%$ of this extract had almost no detectable tumors at the end of the trial. Reduction in colon length was measured as an indicator of inflammation and was attenuated together with tumor formation and growth by bilberry treatment.

Bilberry anthocyanin rich extract was effective also in the genetic Apc $\mathrm{Min} /+^{+}$mouse model, reducing dose-dependently the number of small intestinal adenomas [9]. In another study using this mouse model, freeze dried bilberry reduced only the number, but interestingly not the size of adenomas [38]. Similarly, the number of tumors was reduced by bilberry anthocyanins in $\mathrm{Apc}^{\mathrm{Min} /+}$ mice treated with antibiotics and subsequently infected with enterotoxigenic Bacteroides fragilis, but tumor size was not reported in this study [39]. Freeze dried lingonberry, however, reduced both the number and size of intestinal adenomas [38]. This was the only animal study conducted with a lingonberry treatment and the only study with a whole-berry preparation instead of an anthocyanin rich extract.

In the two studies on a mouse xenograft with subcutaneous CRC tumors, bilberry anthocyanin rich extract alone did not affect tumor volume but enhanced the effectivity of an immune checkpoint inhibitor drug in combination therapy [36,37]. Enhancement of tumor control was associated with tumor immune filtration in the study of Liu et al., and was abolished with antibiotic treatment in Wang et al. publication, suggesting a role for modulation of gut microbiota and/or immune responses by bilberry anthocyanin rich extract [36,37]. 
Table 1. Colorectal cancer: Main results of animal studies.

\begin{tabular}{|c|c|c|c|c|c|c|}
\hline Publication & Berry & Population/Model & Endpoint & Method & Treatment & Effect \\
\hline $\begin{array}{l}\text { Lala et al., } 2006 \text { [34] } \\
\text { (a) }\end{array}$ & Bilberry & $\begin{array}{l}\text { Fisher } 344 \text { male rats } \\
\text { treated with } \\
\text { azoxymethane } \\
n=10 \text { per group }\end{array}$ & $\begin{array}{l}\text { 1. Number and } \\
\text { multiplicity of colonic } \\
\text { aberrant crypt foci (ACF) } \\
\text { 2. Colonic cell } \\
\text { proliferation }\end{array}$ & $\begin{array}{l}\text { 1. Staining and light } \\
\text { microscopy of colons } \\
\text { 2. Proliferating cell } \\
\text { nuclear antigen } \\
\text { immunohistochemistry }\end{array}$ & $\begin{array}{l}\text { AIN-93 powdered diet } \\
\text { supplemented with } 3.85 \\
\text { g monomeric } \\
\text { anthocyanin bilberry } \\
\text { ARE/kg for } 14 \text { weeks }\end{array}$ & $\begin{array}{l}\text { 1. Significantly reduced number } \\
\text { of total and large ACF compared } \\
\text { to control. Number of large ACF } \\
\text { was reduced by } 70 \% \\
\text { 2. Significantly decreased colonic } \\
\text { cellular proliferation by nearly } \\
50 \%\end{array}$ \\
\hline $\begin{array}{l}\text { Cooke et al., } 2006 \text { [9] } \\
\text { (b) }\end{array}$ & Bilberry & $\begin{array}{l}\text { Apc }{ }^{\mathrm{Min} /+} \text { mice } \\
n=16 \text { per group }\end{array}$ & $\begin{array}{l}\text { Number, location, and } \\
\text { size of adenomas in } \\
\text { gastrointestinal tract }\end{array}$ & $\begin{array}{l}\text { Dissection after } \\
\text { termination }\end{array}$ & $\begin{array}{l}\text { Standard diet with ARE } \\
\text { from bilberry } \\
\text { (Mirtoselect): Group 1: } \\
0.03 \% \text {, Group 2: } 0.1 \% \text {, } \\
\text { Group 3: } 0.3 \% \\
w / w \text { of ARE in diet for } \\
12 \text { weeks }\end{array}$ & $\begin{array}{l}\text { Significantly and } \\
\text { dose-dependently reduced } \\
\text { adenoma load compared to } \\
\text { control (number reduced by } 30 \% \\
\text { with highest dose). Reduced } \\
\text { particularly the number of small } \\
\text { adenomas dose-dependently in } \\
\text { the small intestine }\end{array}$ \\
\hline $\begin{array}{l}\text { Misikangas et al., } \\
2007 \text { [38] } \\
\text { (b) }\end{array}$ & $\begin{array}{l}\text { Bilberry and } \\
\text { lingonberry }\end{array}$ & $\begin{array}{l}\text { C57BL } / 6 \mathrm{~J} \mathrm{Min} /+ \text { mice, } \\
\text { male and female } \\
n=10-12 \text { in group }\end{array}$ & Sum of adenoma areas & $\begin{array}{l}\text { Dissection after } \\
\text { termination }\end{array}$ & $\begin{array}{l}10 \% w / w \text { freeze-dried } \\
\text { bilberry or lingonberry } \\
\text { in High-fat AIN93 diet } \\
\text { for } 10 \text { weeks }\end{array}$ & $\begin{array}{l}\text { Both berries significantly } \\
\text { inhibited number of adenomas by } \\
\text { 15-30\% compared to control. } \\
\text { Bilberry did not reduce the size of } \\
\text { adenomas, but lingonberry } \\
\text { reduced adenoma burden by } 60 \%\end{array}$ \\
\hline $\begin{array}{l}\text { Lippert et al., } 2017 \\
\text { [35] } \\
\text { (a) }\end{array}$ & Bilberry & $\begin{array}{l}\text { Female Balb/c mice, } \\
\text { Azoxymethane/dextran } \\
\text { sodium sulphate mouse } \\
\text { model } \\
n=50 \text { mice divided in } 3 \\
\text { groups }\end{array}$ & $\begin{array}{l}\text { Tumor growth and } \\
\text { number }\end{array}$ & $\begin{array}{l}\text { Colonoscopy } \\
\text { at weeks } 4 \text { and } 9, \\
\text { macroscopic and } \\
\text { microscopic analysis } \\
\text { after termination at week } \\
9\end{array}$ & $\begin{array}{l}\text { Bilberry } \\
\text { anthocyanin-rich extract } \\
1 \% \text { or } 10 \% w / w \text { of extract } \\
\text { in diet for } 10 \text { weeks }\end{array}$ & $\begin{array}{l}\text { Significantly smaller and less } \\
\text { (almost no detectable tumors) in } \\
10 \% \text { ARE fed mice compared to } \\
\text { controls or mice fed with } 1 \% \\
\text { extract. Smaller and less tumors } \\
\text { also with } 1 \% \text { extract compared to } \\
\text { control, but difference not } \\
\text { statistically significant }\end{array}$ \\
\hline
\end{tabular}


Table 1. Cont.

\begin{tabular}{|c|c|c|c|c|c|c|}
\hline Publication & Berry & Population/Model & Endpoint & Method & Treatment & Effect \\
\hline $\begin{array}{l}\text { Mudd et al., } 2020 \text { [39] } \\
\text { (b) }\end{array}$ & Bilberry & $\begin{array}{l}\text { Apc }{ }^{\mathrm{Min} /+} \text { mice } \\
\text { treated with antibiotics } \\
\text { and infected with } \\
\text { enterotoxigenic } \\
\text { Bacteroides fragilis } \\
n=6 \text { per group }\end{array}$ & Tumor number & $\begin{array}{l}\text { Dissection after } \\
\text { termination }\end{array}$ & $\begin{array}{l}\text { Bilberry anthocyanin } \\
\text { extract } \\
\text { on average } 8.6 \mathrm{mg} / \mathrm{kg} \\
\text { body weight by gavage } 3 \\
\text { times a week for } 4 \text { weeks }\end{array}$ & $\begin{array}{l}\text { Significantly reduced tumor } \\
\text { number } \\
\text { approx. } 50 \% \text { compared to control }\end{array}$ \\
\hline $\begin{array}{l}\text { Wang et al., } 2020 \text { [37] } \\
\text { (c) }\end{array}$ & Bilberry & $\begin{array}{l}\text { Female C57BL/ } 6 \text { mice } \\
\text { subcutaneously } \\
\text { inoculated with } \\
\text { MC38-OVA } \\
\text { cells, receiving immune } \\
\text { checkpoint inhibitor } \\
\text { injections } \\
n=6 \text { per group }\end{array}$ & Tumor volume & $\begin{array}{l}\text { Measured every } 3-4 \\
\text { days with } \\
\text { an electronic caliper }\end{array}$ & $\begin{array}{l}\text { Bilberry anthocyanin } \\
\text { extract } \\
156 \text { ug of anthocyanins } \\
\text { daily } \\
\text { for } 27 \text { days }\end{array}$ & $\begin{array}{l}\text { Extract alone did not affect tumor } \\
\text { volume compared to control, but } \\
\text { significantly enhanced the effect } \\
\text { of the drug, possibly through } \\
\text { modulation of gut microbiota } \\
\text { (effect was abolished by antibiotic } \\
\text { treatment) }\end{array}$ \\
\hline $\begin{array}{l}\text { Liu et al., } 2020 \text { [36] } \\
\text { (c) }\end{array}$ & Bilberry & $\begin{array}{l}\text { Female C57BL/ } 6 \text { mice } \\
\text { subcutaneously } \\
\text { inoculated with } \\
\text { MC38-OVA } \\
\text { cells, receiving immune } \\
\text { checkpoint inhibitor } \\
\text { injections } \\
n=6 \text { per group }\end{array}$ & Tumor volume & $\begin{array}{l}\text { Measured every 3-4 } \\
\text { days with } \\
\text { an electronic caliper }\end{array}$ & $\begin{array}{l}\text { Standardized bilberry } \\
\text { ARE (Mirtoselect, Indena } \\
\text { S.p.A. Italy) } \\
25 \text { mg bilberry } \\
\text { extract/ } \mathrm{kg} \text { body weight } \\
\text { daily for } 2 \text { weeks }\end{array}$ & $\begin{array}{l}\text { Extract was not tested alone but } \\
\text { enhanced therapeutic effects of } \\
\text { the drug. Enhanced tumor } \\
\text { immune filtration was associated } \\
\text { with improvement of tumor } \\
\text { control. }\end{array}$ \\
\hline
\end{tabular}


In these reviewed animal studies, formation and growth of intestinal tumors or pre-cancerous lesions was inhibited with $10 \%(w / w)$ of freeze-bilberry or lingonberry in diet [38], from a few grams $/ \mathrm{kg}$ to $10 \%(w / w)$ of bilberry anthocyanin extract in diet $[9,35]$, and with $3.85 \mathrm{~g}$ of bilberry anthocyanin rich extract $/ \mathrm{kg}$ in diet [34]. When administered separately, $8.6 \mathrm{mg} / \mathrm{kg}$ of bilberry anthocyanin extract 3 times per week reduced tumor number by approximately $50 \%$ compared to the control [39]. In the studies on xenograft models, $156 \mu \mathrm{g} /$ day per mouse and $25 \mathrm{mg} / \mathrm{kg}$ body weight daily of bilberry anthocyanin extract were sufficient for enhancing a therapeutic effect of an immune checkpoint inhibitor drug [36,37].

\subsection{In Vitro Studies on Colorectal Cancer}

Studies on CRC cell lines are presented in Table 2. A total of 10 studies with a bilberry treatment, 5 with a lingonberry treatment, and 3 with both were identified. In these studies, berry extracts were found to reduce CRC cell proliferation [39-51] and induce apoptosis $[44,49,52]$. Furthermore, tumor cells were more sensitive than non-tumorigenic cells to the anti-proliferative effects of investigated berry extracts $[39,43]$.

The inhibition of cell proliferation was most commonly measured, and various bilberry extracts were effective in all studies in which their effect on the growth of CRC cells were analyzed $[39,41,43-45,47-51]$. Similarly, various lingonberry extracts inhibited proliferation in all studies which tested lingonberry extracts on CRC cell proliferation [40-42,44,46]. Within individual studies, higher concentrations of various berry extracts and longer exposure times generally led to higher inhibition of tumor cells, but similar consistency could not be seen when results of all studies were compared, possibly due to different chemical compositions of tested extracts. Only two studies compared inhibition of tumor cells to that of non-tumorigenic digestive tract cells, both indicating greater sensitivity of tumor cells [39,43]. Zhao et al. (2004) found that tumor cells responded to bilberry extract at lower concentrations $(25 \mu \mathrm{g}$ of monomeric anthocyanin $/ \mathrm{mL}$ ) and at earlier timepoints (48 and $72 \mathrm{~h}$ ) compared to non-tumorigenic cells, with significant growth inhibition of $24 \%$ and $53 \%$, respectively [43]. Time-dependent inhibition was observed with higher concentrations (50 and 75 of monomeric anthocyanin $/ \mathrm{mL}$ ), whereas non-tumorigenic immortalized NCM460 cells were significantly inhibited only after $72 \mathrm{~h}$ with all concentrations. Similarly, in the study of Mudd et al. (2020), non-tumorigenic colon cells were less sensitive than tumor cells to bilberry anthocyanins, with IC50 values of 124 and $75 \mu \mathrm{mol} / \mathrm{mL}$ for tumorigenic HT-29 and HCT116, respectively, and $1050 \mu \mathrm{mol} / \mathrm{mL}$ for non-tumorigenic NCM460 cells [39]. 
Table 2. Colorectal cancer: Main results of in vitro studies.

\begin{tabular}{|c|c|c|c|c|c|c|}
\hline Study & Berry & Cell Line & Endpoints & Methods & Exposure & Effect \\
\hline $\begin{array}{l}\text { Katsube et al., } \\
2003 \text { [41] }\end{array}$ & $\begin{array}{l}\text { Bilberry, } \\
\text { lingonberry }\end{array}$ & HCT116 & $\begin{array}{l}\text { 1. Cell growth } \\
\text { inhibition } \\
\text { 2. Induction of } \\
\text { apoptosis (for } \\
\text { bilberry only) }\end{array}$ & $\begin{array}{l}\text { 1.Cell counting by } \\
\text { trypan blue exclusion } \\
\text { 2. DNA extraction and } \\
\text { agarose gel electrophore- } \\
\text { sis / Analysis of nuclear } \\
\text { morphology by } 1 \mathrm{mM} \\
\text { bisbenzimide staining }\end{array}$ & $\begin{array}{l}\text { 1. } 2-4 \mathrm{mg} \text { dry weight } / \mathrm{mL} \text { of } \\
\text { bilberry /lingonberry ethanol extract for } \\
48 \mathrm{~h} \text {, in addition bilberry ethanol } \\
\text { extract for } 24 \text { and } 48 \mathrm{~h} \text { with } 0.5-4 \mathrm{mg} \\
\text { dry weight } / \mathrm{mL} \\
2.4 \mathrm{mg} / \mathrm{mL} \text { bilberry extract for } 24 \mathrm{~h}\end{array}$ & $\begin{array}{l}\text { 1. Bilberry and lingonberry ethanol extracts } \\
\text { strongly inhibited the growth of HCT } 116 \text {. } \\
\text { Bilberry inhibited cell growth }>50 \% \text { with } \\
2-4 \mathrm{mg} / \mathrm{mL} \text {. Over } 50 \% \text { inhibition was } \\
\text { achieved also with } 4 \mathrm{mg} / \mathrm{mL} \text { lingonberry } \\
\text { extract } \\
\text { 2. Bilberry extract did not induce apoptosis }\end{array}$ \\
\hline $\begin{array}{l}\text { Olsson et al., } \\
2004 \text { [42] }\end{array}$ & Lingonberry & HT-29 & $\begin{array}{l}\text { Cell growth } \\
\text { inhibition }\end{array}$ & WST- 1 assay & $\begin{array}{l}\text { Lingonberry ethanol } \\
\text { extract/anthocyanin fraction } \\
0.025-0.5 \% \text { of plant dry matter of total } \\
\text { weight in the wells } \\
\text { for } 24 \mathrm{~h}\end{array}$ & $\begin{array}{l}\text { Decreased proliferation significantly and } \\
\text { dose-dependently. GI50 between } 0.25 \% \text { and } \\
0.5 \% \text { of plant dry matter in the wells } \\
\text { Anthocyanin fraction was less effective }\end{array}$ \\
\hline $\begin{array}{l}\text { Zhao et al., } \\
2004 \text { [43] }\end{array}$ & Bilberry & $\begin{array}{l}\text { HT- } 29 \\
\text { NCNM460 } \\
\text { (Immorta-lized } \\
\text { colon cell line) }\end{array}$ & $\begin{array}{l}\text { Cell growth } \\
\text { inhibition }\end{array}$ & $\begin{array}{l}\text { Sulphorhodamine B } \\
\text { assay }\end{array}$ & $\begin{array}{l}\text { Bilberry anthocyanin-rich extract } \\
\text { (Artemis International Inc.) } \\
25-75 \mu \mathrm{g} \text { of monomeric } \\
\text { anthocyanin } / \mathrm{mL} \\
\text { for } 24 / 48 / 72 \mathrm{~h}\end{array}$ & $\begin{array}{l}\text { Significantly and time-dependently } \\
\text { inhibited growth of HT- } 29 \text { with } 50-75 \\
\mu \mathrm{g} / \mathrm{mL} \text { of monomeric anthocyanin from } 24 \\
\mathrm{~h} \text { on, with } 25 \mu \mathrm{g} / \mathrm{mL} \text { from } 48 \mathrm{~h} \text { on. Over } \\
50 \% \text { inhibition for all concentrations after } \\
72 \mathrm{~h} \text {. } \\
\text { NCNM } 460 \text { was only inhibited after } 72 \mathrm{~h}\end{array}$ \\
\hline $\begin{array}{l}\text { Wu et al., } \\
2007 \text { [44] }\end{array}$ & $\begin{array}{l}\text { Bilberry, } \\
\text { lingonberry }\end{array}$ & HT-29 & $\begin{array}{l}\text { 1. Cell growth } \\
\text { inhibition } \\
\text { 2.Induction of } \\
\text { apoptosis }\end{array}$ & $\begin{array}{l}\text { 1.Total cell count } \\
\text { determined using } \\
\text { SYTOX-green } \\
\text { 2.DNA fragmentation by } \\
\text { agarose gel } \\
\text { electrophoresis }\end{array}$ & $\begin{array}{l}\text { 1.5- } 60 \mathrm{mg} / \mathrm{mL} \text { bilberry/lingonberry } \\
\text { methanol extract } \\
\text { for } 24 \mathrm{~h} \\
\text { 2. } 5-60 \mathrm{mg} / \mathrm{mL} \text { bilberry extract } \\
\text { for } 48 \mathrm{~h}\end{array}$ & $\begin{array}{l}\text { 1. Both inhibited cell growth significantly. } \\
\text { Bilberry } \\
\text { GI50 = approx. } 15 \mathrm{mg} / \mathrm{mL} \\
\text { Lingonberry } \\
\text { GI50 = } 60 \mathrm{mg} / \mathrm{mL} \\
\text { 2. Bilberry induced apoptosis with } 20-60 \\
\mathrm{mg} / \mathrm{mL}\end{array}$ \\
\hline
\end{tabular}


Table 2. Cont.

\begin{tabular}{|c|c|c|c|c|c|c|}
\hline Study & Berry & Cell Line & Endpoints & Methods & Exposure & Effect \\
\hline $\begin{array}{l}\text { Jing et al., } \\
2008 \text { [45] }\end{array}$ & Bilberry & HT-29 & $\begin{array}{l}\text { Cell growth } \\
\text { inhibition }\end{array}$ & $\begin{array}{l}\text { Sulphorhodamine B } \\
\text { assay }\end{array}$ & $\begin{array}{l}\text { Bilberry anthocyanin-rich extract } \\
\text { (Artemis International, Inc.) } \\
0-200 \mu \mathrm{g} / \mathrm{mL} \text { cyanidin-3-glucoside } \\
\text { equivalents for } 48 \mathrm{~h}\end{array}$ & $\begin{array}{l}\text { Dose-dependent inhibitory effect on the } \\
\text { growth of HT29. } \\
\text { GI50 }=32.2 \mu \mathrm{g} / \mathrm{mL}\end{array}$ \\
\hline $\begin{array}{l}\text { McDougall } \\
\text { et al., } 2008 \\
{[46]}\end{array}$ & Lingonberry & Caco-2 & $\begin{array}{l}\text { Cell growth } \\
\text { inhibition }\end{array}$ & Dojindo CCK-8 kit & $\begin{array}{l}\text { Lingonberry acetonitrile extract } \\
\text { (bound fraction from solid phase } \\
\text { extraction only) } 25-75 \mu \mathrm{g} \text { of gallic acid } \\
\text { equivalents } / \mathrm{mL} \text { for } 72 \mathrm{~h}\end{array}$ & $\begin{array}{l}\text { Inhibited cell growth in a dose-dependent } \\
\text { manner, GI50 } 38.3 \mu \mathrm{g} \text { GAE } / \mathrm{mL}\end{array}$ \\
\hline $\begin{array}{l}\text { Schantz et al., } \\
2010[52]\end{array}$ & Bilberry & $\begin{array}{l}\text { HT-29 } \\
\text { Caco-2 }\end{array}$ & $\begin{array}{l}\text { 1.Cytotoxicity } \\
\text { 2. Induced DNA } \\
\text { damage }\end{array}$ & $\begin{array}{l}\text { 1. Alamar blue } \\
\text { 2. Comet Assay }\end{array}$ & $\begin{array}{l}\text { Bilberry extract from European bilberry } \\
\text { pomace (Kaden Biochemicals, } \\
\text { Hamburg, Germany) } \\
\text { 1. } 5-500 \mu \mathrm{g} / \mathrm{mL} \text { for } 1 \text { and } 24 \mathrm{~h} \\
\text { 2. } 0.01-500 \mu \mathrm{g} / \mathrm{mL} \text { for } 1 \text { and } 24 \mathrm{~h}\end{array}$ & $\begin{array}{l}\text { 1.Significant effect only on HT-29, with } 500 \\
\mu \mathrm{g} / \mathrm{mL} \text { only. EC50 was not reached } \\
\text { 2. Decreased induced DNA damage only in } \\
\text { Caco-2 cells, with } 5-100 \mu \mathrm{g} / \mathrm{ml}\end{array}$ \\
\hline $\begin{array}{l}\text { Esselen et al., } \\
2011 \text { [47] }\end{array}$ & Bilberry & HT-29 & $\begin{array}{l}\text { 1. Cell growth } \\
\text { inhibition } \\
\text { 2. DNA integrity } \\
\text { 3. Drug } \\
\text { interaction with } \\
\text { topoisomerase } \\
\text { poisons }\end{array}$ & $\begin{array}{l}\text { 1. Sulphorhodamine B } \\
\text { assay } \\
\text { 2. Comet assay } \\
\text { 3. ICE assay with } \\
\text { topoisomerase poisons } \\
\text { Camptotecin and } \\
\text { Doxorubicin }\end{array}$ & $\begin{array}{l}\text { Bilberry industrial ARE (Indena, Milan, } \\
\text { Italy) } \\
\text { 1. } 50-500 \mu \mathrm{g} / \mathrm{mL} \text { for } 72 \mathrm{~h} \\
\text { 2. } 1-0 \mu \mathrm{g} / \mathrm{mL} \text { for } 1 \mathrm{~h} \\
\text { 3. } 0.01-50 \mu \mathrm{g} / \mathrm{mL}, 30 \mathrm{~min} \text { pre }+1 \mathrm{~h} \\
\text { coincubation }\end{array}$ & $\begin{array}{l}\text { 1. Bilberry ARE inhibited HT29 growth } \\
\text { dose-dependently. GI50 was not reached } \\
\text { 2. Bilberry ARE increased the rate of DNA } \\
\text { strand brakes, but no additional oxidative } \\
\text { damage observed } \\
\text { 3.DNA-damaging effects and cytotoxicity } \\
\text { of both drugs were inhibited by bilberry } \\
\text { ARE }\end{array}$ \\
\hline $\begin{array}{l}\text { Fan et al., } \\
2011[48]\end{array}$ & Lingonberry & HT-29 & $\begin{array}{l}\text { Cell growth } \\
\text { inhibition }\end{array}$ & MTS assay & $\begin{array}{l}\text { Lingonberry acetone extract } \\
20-80 \mathrm{mg} / \mathrm{mL} \\
\text { for } 48 \mathrm{~h}\end{array}$ & $\begin{array}{l}\text { Proliferation significantly inhibited in a } \\
\text { dose-dependent manner, GI50 approx. } 35 \\
\mathrm{mg} / \mathrm{mL}\end{array}$ \\
\hline $\begin{array}{l}\text { Kropat et al., } \\
2013[50]\end{array}$ & Bilberry & HT-29 & $\begin{array}{l}\text { Cell growth } \\
\text { inhibition }\end{array}$ & $\begin{array}{l}\text { Living cells counted } \\
\text { after staining with } \\
\text { trypan blue }\end{array}$ & $\begin{array}{l}\text { Pomace methanol extract from } \\
\text { European bilberry } \\
10-400 \mu \mathrm{g} / \mathrm{mL} \\
\text { for } 72 \mathrm{~h}\end{array}$ & $\begin{array}{l}\text { Inhibited cell growth significantly, with } \\
\text { concentrations above } 100 \mu \mathrm{g} / \mathrm{mL} \text {. GI50 } \\
\text { between } 200 \text { and } 400 \mu \mathrm{g} / \mathrm{mL}\end{array}$ \\
\hline
\end{tabular}


Table 2. Cont

\begin{tabular}{|c|c|c|c|c|c|c|}
\hline Study & Berry & Cell Line & Endpoints & Methods & Exposure & Effect \\
\hline $\begin{array}{l}\text { Aaby et al., } \\
2013 \text { [49] }\end{array}$ & Bilberry & $\begin{array}{l}\text { Caco-2 } \\
\text { HT-29 } \\
\text { HCT116 }\end{array}$ & $\begin{array}{l}\text { 1. Cell growth in- } \\
\text { hibition/viability } \\
\text { 2. Apoptosis } \\
\text { (HT-29 only) }\end{array}$ & $\begin{array}{l}\text { 1. MTT Assay } \\
\text { 2. Cell Death Detection } \\
\text { ELISAPLUS Assay with } \\
\text { BCA protein assay }\end{array}$ & $\begin{array}{l}\text { Bilberry extract, raw juice and press } \\
\text { residue extracts obtained from } \\
\text { extraction in different temperatures } \\
(40 / 60 / 80 / 100 \mathrm{C}) \\
\text { 1. } 30 \text { min exposure to } 75-250 \mathrm{mg} \text { GAE/1. } \\
\text { Measurement after } 24 \mathrm{~h} \\
\text { 2. } 24 \text {-h exposure with } 75-250 \mathrm{mg} \\
\text { GAE/1 of press residue extracts }\end{array}$ & $\begin{array}{l}\text { 1. All extracts inhibited proliferation of all } \\
\text { cell lines. Dose-response inhibition of all } \\
\text { extracts on all cell lines, except for raw juice } \\
\text { on HT-29 and HCT } 116 \text {. GI50 of Caco- } 2 \text { and } \\
\text { HCT } 116 \text { was reached with all extracts, of } \\
\text { HT- } 29 \text { only press residue extracts from } \\
80-100^{\circ} \mathrm{C} \text { temperatures } \\
\text { 2. Dose response for both tested press } \\
\text { residue extracts (extracted in } 40 / 100^{\circ} \mathrm{C} \\
\text { temperature) }\end{array}$ \\
\hline $\begin{array}{l}\text { Brown et al., } \\
2014 \text { [53] }\end{array}$ & Lingonberry & $\begin{array}{l}\text { HT-29 } \\
\text { HT115 }\end{array}$ & $\begin{array}{l}\text { 1. Cytotoxic } \\
\text { activity } \\
\text { 2. Inhibition of } \\
\text { invasion and } \\
\text { migration }\end{array}$ & $\begin{array}{l}\text { 1. MTT assay } \\
\text { 2. Matrigel invasion and } \\
\text { migration assays }\end{array}$ & $\begin{array}{l}\text { Lingonberry methanol extract prepared } \\
\text { to: } \\
\text { IVDL: In vitro digested extract and } \\
\text { IVFL: In vitro fermented extract } \\
\text { both } 3-50 \mu \mathrm{g} / \mathrm{mL} \text { GAE for } 24 \mathrm{~h} \\
\text { Ileal fluid after lingonberry ingestion, } \\
3-200 \mu \mathrm{g} / \mathrm{mL} \text { for } 24 \mathrm{~h}\end{array}$ & $\begin{array}{l}\text { 1. No cytotoxic activity for any exposure } \\
\text { 2. IVDL and IVFL had significant } \\
\text { anti-invasive effects, migration } \\
\text { not affected }\end{array}$ \\
\hline $\begin{array}{l}\text { Tumbas } \\
\text { Šaponjac } \\
\text { et al., } 2014 \\
\text { [51] }\end{array}$ & Bilberry & HT-29 & $\begin{array}{l}\text { Cell growth } \\
\text { inhibition }\end{array}$ & $\begin{array}{l}\text { Sulphorhodamine B } \\
\text { assay }\end{array}$ & $\begin{array}{l}\text { Bilberry extract fractions } \\
\text { Fraction 1: Polar substances } \\
\text { Fraction 2: } 6 \text { flavonols detected } \\
\text { Fraction3: } 8 \text { phenolic acids identified } \\
62.5-1000 \mu \mathrm{g} \text { of dried fraction } / \mathrm{mL} \\
\text { for } 48 \mathrm{~h}\end{array}$ & $\begin{array}{l}\text { Fractions } 2 \text { and } 3 \text { suppressed cell growth } \\
\text { significantly and dose-dependently. Over } \\
50 \% \text { growth inhibition achieved with } \geq 125 \\
\mu \mathrm{g} / \mathrm{mL} \text { of fraction } 2 \text {, and with } \geq 500 \mu \mathrm{g} / \mathrm{mL} \\
\text { of fraction } 3 \text {. Fraction } 1 \text { resulted in less than } \\
10 \% \text { inhibition with } 250-500 \mu \mathrm{g} / \mathrm{mL} \text {. }\end{array}$ \\
\hline
\end{tabular}


Table 2. Cont

\begin{tabular}{|c|c|c|c|c|c|c|}
\hline Study & Berry & Cell Line & Endpoints & Methods & Exposure & Effect \\
\hline $\begin{array}{l}\text { Minker et al., } \\
2015 \text { [55] }\end{array}$ & $\begin{array}{l}\text { Bilberry, } \\
\text { lingonberry }\end{array}$ & $\begin{array}{l}\text { SW840 (primary) } \\
\text { SW620 } \\
\text { (metastasis) }\end{array}$ & $\begin{array}{l}\text { Induction of } \\
\text { apoptosis }\end{array}$ & $\begin{array}{l}\text { Flow cytometry, cell } \\
\text { surface } \\
\text { phosphatidylserine } \\
\text { detection, caspase } 8 \text { and } \\
\text { caspase } 9 \text { activation }\end{array}$ & $\begin{array}{l}\text { Bilberry/lingonberry } \\
\text { proanthocyanidins extracted in } \\
\text { acetone } / \text { methanol } \\
5-75 \mu \mathrm{g} / \mathrm{mL} \text { of each fraction } \\
\text { during seeding and for } 24 \mathrm{~h} \text { for SW620 } \\
\text { and } 48 \mathrm{~h} \text { for SW } 480\end{array}$ & $\begin{array}{l}\text { Bilberry induced apoptosis via extrinsic } \\
\text { pathway } \\
\text { EC50 for bilberry treated SW620: } 24.7 \\
\mu \mathrm{g} / \mathrm{mL} \text { and SW480: } 25.2 \mu \mathrm{g} / \mathrm{mL} \\
\text { EC50 for lingonberry treated } \\
\text { SW620: } 24.3 \mu \mathrm{g} / \mathrm{mL} \\
\text { SW480: } 24.7 \mu \mathrm{g} / \mathrm{mL}\end{array}$ \\
\hline $\begin{array}{l}\text { Borowiec } \\
\text { et al., } 2016 \\
{[56]}\end{array}$ & Bilberry & Caco-2 & $\begin{array}{l}\text { 1. Cell viability } \\
\text { 2. Genotoxicity }\end{array}$ & $\begin{array}{l}\text { 1. MTT assay } \\
\text { 2. Single cell } \\
\text { electrophoresis, also } \\
\text { under oxidative stress } \\
(\mathrm{H} 2 \mathrm{O} 2)\end{array}$ & $\begin{array}{l}\text { Bilberry juice extract (no solvent used) } \\
\text { 1. } 12.5-400 \mu \mathrm{g} \text { dry mass } / \mathrm{mL} \\
\text { for } 48 \mathrm{~h} \\
\text { 2. } 100 \mu \mathrm{g} \text { dry mass } / \mathrm{mL} 48 \mathrm{~h}\end{array}$ & $\begin{array}{l}\text { 1. Viability of Caco-2 was significantly but } \\
\text { modestly inhibited only with } 400 \mu \mathrm{g} / \mathrm{mL} \\
\text { (approx. } 20 \% \text { inhibition) } \\
\text { 2. Not genotoxic }\end{array}$ \\
\hline $\begin{array}{l}\text { Mudd et al., } \\
2020 \text { [39] }\end{array}$ & Bilberry & $\begin{array}{l}\text { HCT } 116 \\
\text { HT-29 } \\
\text { CCD-18Co } \\
\text { (Human colon) }\end{array}$ & $\begin{array}{l}\text { Inhibition of pro- } \\
\text { liferation/Cell } \\
\text { viability }\end{array}$ & MTT assay & $\begin{array}{l}\text { Bilberry anthocyanin extract } \\
\text { concentrations up to } 200 \mu \mathrm{mol} / \mathrm{L}\end{array}$ & $\begin{array}{l}\text { Bilberry anthocyanin extract inhibited } \\
\text { proliferation of tumor cells more than colon } \\
\text { cells } \\
\text { IC50 values for HT-29: } 124 \mu \mathrm{mol} / \mathrm{L} \\
\text { HCT-116: } 75 \mu \mathrm{mol} / \mathrm{L} \\
\text { CCD-18Co: } 1050 \mu \mathrm{mol} / \mathrm{L}\end{array}$ \\
\hline $\begin{array}{l}\text { Vilkickyte } \\
\text { et al., } 2020 \\
{[40]}\end{array}$ & Lingonberry & HT-29 & Cell viability & MTT assay & $\begin{array}{l}\text { Lingonberry extracted in acetone and } \\
\text { phenolic fractions subsequently isolated } \\
\text { with column chromatography }\end{array}$ & $\begin{array}{l}\text { Lingonberry extract fractions reduced } \\
\text { viability with EC50 values approx. } 0.05-1.1 \\
\mathrm{mg} / \mathrm{mL} \text {, Fraction } 4 \text { rich in } \\
\text { proanthocyanidins being the most effective }\end{array}$ \\
\hline
\end{tabular}


Some in vitro studies reported cytotoxicity or cell viability instead of inhibition of proliferation, with inconsistent results $[47,52-54,56]$. Mild toxicity was reached with $400 \mathrm{ug} / \mathrm{mL}$ of bilberry juice on Caco-2 [56] and with $500 \mathrm{ug} / \mathrm{mL}$ of bilberry pomace extract on HT-29 CRC cells [52]. Bilberry decoction and infusion teas were cytotoxic to LS147 CRC cells with approximately $180 \mathrm{ug} / \mathrm{mL}$ EC50 values [54]. However, no toxicity was detected for $4 \mathrm{mg} / \mathrm{mL}$ of bilberry extract on HCT116 [41], or for in vitro digested or fermented lingonberry extracts on HT-29 or HT115 with concentrations below $50 \mathrm{ug} / \mathrm{mL}$ [53]. On the other hand, bilberry reduced toxicity of topoisomerase poisons in the study of Esselen et al., raising the possibility of counteracting therapeutic toxicity of chemotherapy [47].

Induction of apoptosis in CRC cells was also investigated [41,44,49,52]. Bilberry extracts induced apoptosis in HT-29 cells with concentrations above $20 \mathrm{mg} / \mathrm{mL}[44,49]$ but not in HCT116 with a concentration of $4 \mathrm{mg} / \mathrm{mL}$ [41]. Proanthocyanin-rich extracts of both lingonberry and bilberry induced apoptosis in SW820 and SW640 cells with much lower concentrations; EC50s for both extracts were below $25 \mathrm{ug} / \mathrm{mL}$ [55]. Apoptosis was further investigated in this study with bilberry proanthocyanidin extract and was found to be induced via the extrinsic pathway.

\subsection{Oral Cancer}

No eligible in vivo studies on lingonberry or bilberry and oral cancer were found, but one eligible study on oral carcinoma cells was identified (Table 3). Hoornstra et al. (2018) found that lingonberry juice fermented using Saccharomyces cerevisiae inhibited the proliferation of oral tongue cancer cell lines HSC-3 and SCC25 [57]. Fermented juice also inhibited the invasion of HSC-3, and similarly but not significantly that of SCC25. Migration, however, was not inhibited in either cell line.

Table 3. Oral cancer. Main results of the cell study.

\begin{tabular}{|c|c|c|c|c|}
\hline Publication & $\begin{array}{l}\text { Berry, Cell } \\
\text { Lines }\end{array}$ & Endpoint & Treatment & Effect \\
\hline \multirow{2}{*}{$\begin{array}{l}\text { Hoornstra } \\
\text { et al., } 2018 \\
{[57]}\end{array}$} & \multirow{2}{*}{$\begin{array}{l}\text { Lingonberry, } \\
\text { HSC-3 } \\
\text { SCC25 }\end{array}$} & $\begin{array}{l}\text { 1. Cell proliferation with } \\
\text { enzyme-linked } \\
\text { immunosorbent assay, } \\
\text { 5-bromo-2'-deoxyuridine } \\
\text { BrdU Kit }\end{array}$ & $\begin{array}{l}\text { Lingonberry juice } \\
\text { fermented using } \\
\text { Saccharomyces } \\
\text { Cerevisiae }\end{array}$ & $\begin{array}{l}\text { 1. Significant inhibition at } 2.5 \text { and } \\
5.0 \mathrm{mg} / \mathrm{mL} \text { for both cell lines. } \\
\text { GI50 } 1162 \mu \mathrm{g} / \mathrm{mL} \text { for HSC-3, GI50 } \\
773 \mu \mathrm{g} / \mathrm{mL} \text { for SCC- } 25\end{array}$ \\
\hline & & $\begin{array}{l}\text { 2. Invasion with } 3 \text {-D tumor } \\
\text { myogel spheroid invasion } \\
\text { assay }\end{array}$ & $\begin{array}{l}500,2500,5000 \mathrm{ug} / \mathrm{mL} \\
48 \mathrm{~h} \text { for proliferation } \\
96 \mathrm{~h} \text { for invasion }\end{array}$ & $\begin{array}{l}\text { 2. Significantly reduced invasion } \\
\text { of HSC-3, invasion of SCC- } 25 \text { was } \\
\text { similarly inhibited but result was } \\
\text { not significant }\end{array}$ \\
\hline
\end{tabular}

\section{Discussion}

The aim of this work was to systematically review all in vitro and in vivo English written research publications related to the anticancer effects of lingonberry and bilberry on digestive tract cancers. Published data was mainly focused on bilberry and CRC, and these studies suggest antiproliferative and anti-tumor effect for various bilberry preparations. Only one uncontrolled pilot human trial was identified, in which bilberry anthocyanin-rich extract supplement modestly reduced cancer cells proliferation and increased apoptosis compared to pre-intervention values in CRC tissue after treatment as short as 7 days [10]. Lingonberry preparations showed inhibitory effects comparable to bilberry in cell culture models (Table 2), and freeze-dried lingonberry inhibited adenoma growth even more than bilberry in the only animal experiment conducted on lingonberry [38]. Fermented lingonberry juice inhibited the proliferation of oral carcinoma cells in vitro [57]. Taken together, evidence from human trials is still needed, but all data to date from in vitro and animal models support the antiproliferative and tumor-inhibitory effects of various bilberry and lingonberry preparations on digestive tract cancers. 
In vitro, various bilberry extracts, even at low concentrations (GI50 values $25 \mu \mathrm{g} / \mathrm{mL}-$ $5 \mathrm{mg} / \mathrm{mL}$ ) inhibited proliferation [39,41,43-45,47,50,51], and at higher concentrations (above $20 \mathrm{mg} / \mathrm{mL}$ ) induced apoptosis $[41,44,49]$ in CRC cells. However, proanthocyanidinrich extracts of bilberry and lingonberry induced apoptosis already at far lower concentrations, at the levels of micrograms/mL [55]. In vivo, the proliferation of CRC cells reduced by nearly $50 \%$ in rats with induced carcinogenesis, treated with bilberry anthocyanin rich extract [34]. Small decrease in proliferation and increase in apoptotic index were also detected in tumor tissue of bilberry-treated CRC patients [10]. The specific mechanism behind the antiproliferative activity remains to be specified. Cell growth seems to be inhibited in a cytostatic manner in cell culture [41,43,44,57], but apoptosis may be induced after reaching a concentration threshold [44]. One animal study found that a reduction in colonic cell proliferation in bilberry-treated rats was associated with reduced expression of COX-2, suggesting a link with anti-inflammatory activity [34].

In the animal studies, bilberry extracts inhibited the formation of induced and genetic murine intestinal malignant tumors, or pre-malignant transformations $[9,34,35,38,39]$. Interestingly, bilberry did not reduce the size of small-intestinal adenomas in contrast to lingonberry [38]. In a later publication of this experiment, superior effect of cloudberry compared to bilberry on adenoma size was found to be associated with downregulated gene expression of energy metabolism-related genes and a smaller ratio of intraepithelial to all mucosal CD3+ T lymphocytes in the intestinal mucosa [33]. Bilberry did not affect the formation of subcutaneous tumors in a xenograft mouse model [36,37]. However, the bilberry extract enhanced the effectivity of an immune checkpoint inhibitor drug against subcutaneous tumors $[36,37]$. It is of note that tumors outside the digestive tract would likely be exposed to lower concentrations of berry phytochemicals and their metabolites than tumors in the digestive tract.

The studies we analyzed did not give an exact mechanistical explanation for antitumor activity of lingonberry or bilberry. In the one human pilot study, both cellular proliferation and apoptotic index in the tumor tissue were affected by bilberry extract supplementation [10]. According to the animal studies reviewed here, the anticancer effect of these berries is suggested to come across, at least in part, via modulation of gut microbiota and/or immune responses [33,35-37,39]. These effects could, to some extent, also impact tumorigenesis outside the digestive tract [36,37]. In addition to local effects, systemic effects could be reached via fluctuating postprandial pulses of phytochemicals, slow release of absorbable metabolites in the digestive tract, and accumulation to tissues during prolonged exposure. Besides inhibiting the growth of tumors, berry extracts may inhibit tumor initiation through their DNA-protecting abilities [11,53], supported by the lower number of tumors or pre-cancerous transformations in animals treated with lingonberry and bilberry extracts $[9,34,35,38,39]$.

Anthocyanin-rich extracts are the most frequently examined berry extracts in digestive tract cancers. However, based on our reviewed articles, the anticancer effect of some other berry phytochemicals could be even stronger than that of anthocyanins $[40,42,46]$, or the activity may be synergistic between different compounds. Interestingly, freeze-dried lingonberry reduced adenoma growth in the Apc $\mathrm{Ain} /+^{+}$mouse model more than bilberry [38] regardless of the lower anthocyanin content in lingonberry. Additionally, both lingonberry and bilberry extracts inhibited CRC cell proliferation in vitro [41,44] regardless of their differing phytochemical profiles [16]. In fact, the anthocyanin-rich fraction of lingonberry extract was less antiproliferative than the whole lingonberry extract [32,33], or fractions rich in proanthocyanins $[33,34]$. In addition, bilberry flavonol fraction and phenolic acid fraction both inhibited proliferation of CRC cells, suggesting that antiproliferative activities are shared by different phenolic compounds [51].

The relevance of in vitro studies with berry extracts is debatable, since berry phytochemicals are extensively modified in the digestive tract, and preparations used in cell culture differ in their chemical composure from the metabolites formed during digestion. Therefore, in vitro studies with original berry extracts may have relevance in oral cavity 
cancers, but not necessarily in lower digestive tract neoplasia. Yet, based on effectivity shown in vivo (Table 1), and the potency of different extracts in vitro (Tables 2 and 3), anticancer effects on digestive tract cancers may not require high systemic bioavailability of certain original berry phytochemicals. Some biological activity seems to persist even after extensive modification by human and microbial enzymes [53,57]; however, more research on this subject is needed.

The possible anticancer effects of lingonberry and bilberry are numerous, but exact mechanisms and effective constituents are still unclear and yet to be investigated in cancer prevention and treatment. Regardless of encouraging results from several in vitro and animal studies on bilberry and CRC, only one pilot human trial has been conducted. Deeper understanding of the effective lingonberry and bilberry components, their metabolites, synergy, and underlying biological mechanisms is needed to pave the way for human trials. Animal models have shown the potential of lingonberry and bilberry to inhibit CRC carcinogenesis, but effective dose for humans cannot be deduced based on animal studies. Proving preventive potential in human trials would require multicenter studies with large populations and long follow-ups. Elaborating the anticancer mechanisms of phytochemicals could reveal previously unseen or overlooked aspects of carcinogenesis, and help not only to improve cancer treatment, but also to assess and minimize the cancer risk of an individual. Possible therapeutic benefits of berry phytochemicals [36,37] and potential undesired interactions [47] in combination treatments should also be carefully investigated in future trials.

Due to varying methodology in reviewed studies, meta-analysis could not be conducted. Reporting of experimental replicates and repeats was unclear in some in vitro studies, and the statistical significance of the inhibition of cellular proliferation not always tested, but we did not exclude any controlled studies based on reporting quality. In contrast to our original inclusion criteria, one uncontrolled human pilot study was included, based on the lack of controlled human studies. It should also be noted that many berries have shown anticancer activities [11], but here we went through only research conducted on lingonberry and bilberry, not entirely covering the research field of anticancer effects of wild berries.

\section{Conclusions}

Based on the literature found, bilberry inhibits CRC cell proliferation and tumorigenesis in experimental models, but this effect has not yet been investigated in any placebo controlled human trials. Data also suggested similar activity for lingonberry on CRC and oral cancer cell lines. In addition to anthocyanins, various other berry phytochemicals may have similar and synergistic inhibitory effects on tumor processes. The identification of active berry components, exact local and systemic mechanisms of action, and effective doses require further investigation.

Author Contributions: Conceptualization, T.O., A.K., M.M., and T.S.; methodology, T.O., A.K., and M.M.; formal analysis, T.O., A.K., and M.M.; investigation, T.O., A.K., and M.M.; data curation, T.O.; writing—original draft preparation, T.O.; writing-review and editing, A.K., M.M., T.S., and R.K.; visualization, T.O.; supervision, T.S. and R.K.; project administration, T.S.; funding acquisition, T.S. All authors have read and agreed to the published version of the manuscript.

Funding: The authors acknowledge the funders of this study: Cancer Society of Finland, Sigrid Jusélius Foundation.

Institutional Review Board Statement: Not applicable to this article.

Informed Consent Statement: Not applicable.

Data Availability Statement: No new data were created or analyzed in this study. Data sharing is not applicable to this article. 
Acknowledgments: We thank Katri Larmo from Helsinki University library for kindly guiding us through the systematic search. Open access funding provided by Meilahti Campus Library, University of Helsinki.

Conflicts of Interest: The authors declare no conflict of interest.

\section{References}

1. Aune, D.; Giovannucci, E.; Boffetta, P.; Fadnes, L.T.; Keum, N.; Norat, T.; Greenwood, D.C.; Riboli, E.; Vatten, L.J.; Tonstad, S. Fruit and vegetable intake and the risk of cardiovascular disease, total cancer and all-cause mortality-a systematic review and dose-response meta-analysis of prospective studies. Int. J. Epidemiol. 2017, 46, 1029-1056. [CrossRef]

2. Cirmi, S.; Navarra, M.; Woodside, J.V.; Cantwell, M.M. Citrus fruits intake and oral cancer risk: A systematic review and meta-analysis. Pharmacol. Res. 2018, 133, 187-194. [CrossRef]

3. Ramos, S. Cancer chemoprevention and chemotherapy: Dietary polyphenols and signalling pathways. Mol. Nutr. Food Res. 2008, 52, 507-526. [CrossRef]

4. Crozier, A.; Jaganath, I.B.; Clifford, M.N. Dietary phenolics: Chemistry, bioavailability and effects on health. Nat. Prod. Rep. 2009, 26, 1001-1043. [CrossRef]

5. Pericleous, M.; Mandair, D.; Caplin, M.E. Diet and supplements and their impact on colorectal cancer. J. Gastrointest. Oncol. 2013, 4, 409-423. [CrossRef]

6. Medic, N.; Tramer, F.; Passamonti, S. Anthocyanins in Colorectal Cancer Prevention. A Systematic Review of the Literature in Search of Molecular Oncotargets. Front. Pharmacol. 2019, 10, 675. [CrossRef]

7. Williamson, G.; Clifford, M.N. Colonic metabolites of berry polyphenols: The missing link to biological activity? Br. J. Nutr. 2010, 104 (Suppl. 3), S48-S66. [CrossRef]

8. Vitaglione, P.; Donnarumma, G.; Napolitano, A.; Galvano, F.; Gallo, A.; Scalfi, L.; Fogliano, V. Protocatechuic acid is the major human metabolite of cyanidin-glucosides. J. Nutr. 2007, 137, 2043-2048. [CrossRef]

9. Cooke, D.; Schwarz, M.; Boocock, D.; Winterhalter, P.; Steward, W.P.; Gescher, A.J.; Marczylo, T.H. Effect of cyanidin-3-glucoside and an anthocyanin mixture from bilberry on adenoma development in the ApcMin mouse model of intestinal carcinogenesisrelationship with tissue anthocyanin levels. Int. J. Cancer 2006, 119, 2213-2220. [CrossRef] [PubMed]

10. Thomasset, S.; Berry, D.P.; Cai, H.; West, K.; Marczylo, T.H.; Marsden, D.; Brown, K.; Dennison, A.; Garcea, G.; Miller, A.; et al. Pilot study of oral anthocyanins for colorectal cancer chemoprevention. Cancer Prev. Res. 2009, 2, 625-633. [CrossRef]

11. Bishayee, A.; Haskell, Y.; Do, C.; Siveen, K.S.; Mohandas, N.; Sethi, G.; Stoner, G.D. Potential Benefits of Edible Berries in the Management of Aerodigestive and Gastrointestinal Tract Cancers: Preclinical and Clinical Evidence. Crit. Rev. Food Sci. Nutr. 2016, 56, 1753-1775. [CrossRef] [PubMed]

12. Kottra, G.; Daniel, H. Flavonoid glycosides are not transported by the human Na+/glucose transporter when expressed in Xenopus laevis oocytes, but effectively inhibit electrogenic glucose uptake. J. Pharmacol. Exp. Ther. 2007, 322, 829-835. [CrossRef]

13. Hanahan, D.; Weinberg, R.A. Hallmarks of cancer: The next generation. Cell 2011, 144, 646-674. [CrossRef]

14. Koponen, J.M.; Happonen, A.M.; Mattila, P.H.; Törrönen, A.R. Contents of anthocyanins and ellagitannins in selected foods consumed in Finland. J. Agric. Food Chem. 2007, 55, 1612-1619. [CrossRef]

15. Ovaskainen, M.L.; Törrönen, R.; Koponen, J.M.; Sinkko, H.; Hellström, J.; Reinivuo, H.; Mattila, P. Dietary intake and major food sources of polyphenols in Finnish adults. J. Nutr. 2008, 138, 562-566. [CrossRef] [PubMed]

16. Määttä-Riihinen, K.R.; Kamal-Eldin, A.; Mattila, P.H.; González-Paramás, A.M.; Törrönen, A.R. Distribution and contents of phenolic compounds in eighteen Scandinavian berry species. J. Agric. Food Chem. 2004, 52, 4477-4486. [CrossRef]

17. Eremeeva, N.B.; Makarova, N.V.; Ignatova, D.F.; Bakharev, V.V. Study of potential anti-carcinogenic and antioxidant effects of plant extracts. Izv. Vuzov Prikl. Khimiya I Biotekhnologiya 2020, 10, 613-626. [CrossRef]

18. Holkem, A.T.; Robichaud, V.; Favaro-Trindade, C.S.; Lacroix, M. Chemopreventive Properties of Extracts Obtained from Blueberry (Vaccinium myrtillus L.) and Jabuticaba (Myrciaria cauliflora Berg.) in Combination with Probiotics. Nutr. Cancer Int. J. 2020. [CrossRef]

19. Kobori, M. In Vitro-Screening for Cancer-Suppressive Effect of Food Components. Jpn. Agric. Res. Q. 2003, 37, 159-165. [CrossRef]

20. Yasmin, T.; Sen, C.K.; Hazra, S.; Bagchi, M.; Bagchi, D.; Stohs, S.J. Antioxidant capacity and safety of various anthocyanin berry extract formulations. Res. Commun. Pharmacol. Toxicol. 2003, 8, IV-25-IV-35.

21. Mutanen, M.; Pajari, A.M.; Paivarinta, E.; Misikangas, M.; Rajakangas, J.; Marttinen, M.; Oikarinen, S. Berries as chemopreventive dietary constituents-A mechanistic approach with the ApcMin/+ mouse. Asia Pac. J. Clin. Nutr. 2008, 17 (Suppl. 1), $123-125$.

22. Fan, Z.; Wang, Z. Antioxidant and antiproliferative activities of Lingonberries in vitro. Mod. Food Sci. Technol. 2010, 26, 1081-1086.

23. Rozanova, N.; Zhang, J.Z.; Heck, D.E. Catalytic therapy of cancer with ascorbate and extracts of medicinal herbs. Evid. Based Complement. Altern. Med. 2010, 7, 203-212. [CrossRef] [PubMed]

24. Bertoglio, J.C.; Folatre, I.; Bombardelli, E.; Riva, A.; Morazzoni, P.; Ronchi, M.; Petrangolini, G. Management of gastrointestinal mucositis due to cancer therapies in pediatric patients: Results of a case series with SAMITAL((R)). Future Oncol. 2012, 8, 1481-1486. [CrossRef] [PubMed]

25. Morazzoni, P.; Petrangolini, G.; Bombardelli, E.; Ronchi, M.; Cabri, W.; Riva, A. SAMITAL(R): A new botanical drug for the treatment of mucositis induced by oncological therapies. Future Oncol. 2013, 9, 1717-1725. [CrossRef] 
26. Pawar, D.; Neve, R.S.; Kalgane, S.; Riva, A.; Bombardelli, E.; Ronchi, M.; Petrangolini, G.; Morazzoni, P. SAMITAL®improves chemo/radiotherapy-induced oral mucositis in patients with head and neck cancer: Results of a randomized, placebo-controlled, single-blind Phase II study. Supportive Care Cancer 2013, 21, 827-834. [CrossRef]

27. Du, Q.; Xin, G.; Niu, H.; Huang, W. Hydroquinone analog 4-[(Tetrahydro-2H-pyran-2-yl) oxy] phenol induces C26 colon cancer cell apoptosis and inhibits tumor growth in vivo. Mol. Med. Rep. 2015, 11, 4671-4677. [CrossRef]

28. Sogo, T.; Kumamoto, T.; Ishida, H.; Hisanaga, A.; Sakao, K.; Terahara, N.; Wada, K.; Hou, D.X. Comparison of the Inhibitory Effects of Delphinidin and Its Glycosides on Cell Transformation. Planta Med. 2015, 81, 26-31. [CrossRef]

29. Nilsson, R.; Micic, M.; Filipovic, J.; Sobot, A.V.; Drakulic, D.; Stanojlovic, M.; Joksic, G. Inhibition by blueberries (bilberries) and extract from milk thistle of rat forestomach hyperplasia induced by oral smokeless tobacco (Swedish snus). Regul. Toxicol. Pharmacol. 2016, 76, 94-101. [CrossRef]

30. Munagala, R.; Aqil, F.; Jeyabalan, J.; Agrawal, A.K.; Mudd, A.M.; Kyakulaga, A.H.; Singh, I.P.; Vadhanam, M.V.; Gupta, R.C. Exosomal formulation of anthocyanidins against multiple cancer types. Cancer Lett. 2017, 393, 94-102. [CrossRef]

31. Sezer, E.D.; Oktay, L.M.; Karadadas, E.; Memmedov, H.; Selvi Gunel, N.; Sozmen, E. Assessing Anticancer Potential of Blueberry Flavonoids, Quercetin, Kaempferol, and Gentisic Acid, Through Oxidative Stress and Apoptosis Parameters on HCT-116 Cells. J. Med. Food 2019, 22, 1118-1126. [CrossRef] [PubMed]

32. Szwajgier, D.; Paduch, R.; Kukula-Koch, W.; Polak-Berecka, M.; Wasko, A. Study on Biological Activity of Bread Enriched with Natural Polyphenols in Terms of Growth Inhibition of Tumor Intestine Cells. J. Med. Food 2020, 23, 181-190. [CrossRef] [PubMed]

33. Päivärinta, E.; Niku, M.; Maukonen, J.; Storvik, M.; Heiman-Lindh, A.; Saarela, M.; Pajari, A.M.; Mutanen, M. Changes in intestinal immunity, gut microbiota, and expression of energy metabolism-related genes explain adenoma growth in bilberry and cloudberry-fed Apc(Min) mice. Nutr. Res. 2016, 36, 1285-1297. [CrossRef]

34. Lala, G.; Malik, M.; Zhao, C.; He, J.; Kwon, Y.; Giusti, M.M.; Magnuson, B.A. Anthocyanin-rich extracts inhibit multiple biomarkers of colon cancer in rats. Nutr. Cancer 2006, 54, 84-93. [CrossRef]

35. Lippert, E.; Ruemmele, P.; Obermeier, F.; Goelder, S.; Kunst, C.; Rogler, G.; Dunger, N.; Messmann, H.; Hartmann, A.; Endlicher, E. Anthocyanins Prevent Colorectal Cancer Development in a Mouse Model. Digestion 2017, 95, 275-280. [CrossRef]

36. Liu, X.; Wang, L.; Jing, N.; Jiang, G.; Liu, Z. Biostimulating Gut Microbiome with Bilberry Anthocyanin Combo to Enhance Anti-PD-L1 Efficiency against Murine Colon Cancer. Microorganisms 2020, 8, 175. [CrossRef]

37. Wang, L.; Jiang, G.; Jing, N.; Liu, X.; Li, Q.; Liang, W.; Liu, Z. Bilberry anthocyanin extracts enhance anti-PD-L1 efficiency by modulating gut microbiota. Food Funct. 2020. [CrossRef]

38. Misikangas, M.; Pajari, A.M.; Paivarinta, E.; Oikarinen, S.I.; Rajakangas, J.; Marttinen, M.; Tanayama, H.; Torronen, R.; Mutanen, M. Three Nordic berries inhibit intestinal tumorigenesis in multiple intestinal neoplasia/ + mice by modulating beta-catenin signaling in the tumor and transcription in the mucosa. J. Nutr. 2007, 137, 2285-2290. [CrossRef]

39. Mudd, A.M.; Gu, T.; Munagala, R.; Jeyabalan, J.; Egilmez, N.K.; Gupta, R.C. Chemoprevention of Colorectal Cancer by Anthocyanidins and Mitigation of Metabolic Shifts Induced by Dysbiosis of the Gut Microbiome. Cancer Prev. Res. 2020, 13, 41-51. [CrossRef]

40. Vilkickyte, G.; Raudone, L.; Petrikaite, V. Phenolic fractions from vaccinium vitis-idaea L. And their antioxidant and anticancer activities assessment. Antioxidants 2020, 9, 1261. [CrossRef]

41. Katsube, N.; Iwashita, K.; Tsushida, T.; Yamaki, K.; Kobori, M. Induction of apoptosis in cancer cells by Bilberry (Vaccinium myrtillus) and the anthocyanins. J. Agric. Food Chem. 2003, 51, 68-75. [CrossRef] [PubMed]

42. Olsson, M.E.; Gustavsson, K.E.; Andersson, S.; Nilsson, A.; Duan, R.D. Inhibition of cancer cell proliferation in vitro by fruit and berry extracts and correlations with antioxidant levels. J. Agric. Food Chem. 2004, 52, 7264-7271. [CrossRef] [PubMed]

43. Zhao, C.; Giusti, M.M.; Malik, M.; Moyer, M.P.; Magnuson, B.A. Effects of commercial anthocyanin-rich extracts on colonic cancer and nontumorigenic colonic cell growth. J. Agric. Food Chem. 2004, 52, 6122-6128. [CrossRef]

44. Wu, Q.K.; Koponen, J.M.; Mykkanen, H.M.; Torronen, A.R. Berry phenolic extracts modulate the expression of p21(WAF1) and Bax but not Bcl-2 in HT-29 colon cancer cells. J. Agric. Food Chem. 2007, 55, 1156-1163. [CrossRef] [PubMed]

45. Jing, P.; Bomser, J.A.; Schwartz, S.J.; He, J.; Magnuson, B.A.; Giusti, M.M. Structure-function relationships of anthocyanins from various anthocyanin-rich extracts on the inhibition of colon cancer cell growth. J. Agric. Food Chem. 2008, 56, 9391-9398. [CrossRef]

46. McDougall, G.J.; Ross, H.A.; Ikeji, M.; Stewart, D. Berry extracts exert different antiproliferative effects against cervical and colon cancer cells grown in vitro. J. Agric. Food Chem. 2008, 56, 3016-3023. [CrossRef]

47. Esselen, M.; Fritz, J.; Hutter, M.; Teller, N.; Baechler, S.; Boettler, U.; Marczylo, T.H.; Gescher, A.J.; Marko, D. Anthocyanin-rich extracts suppress the DNA-damaging effects of topoisomerase poisons in human colon cancer cells. Mol. Nutr. Food Res. 2011, 55 (Suppl. 1), S143-S153. [CrossRef]

48. Fan, Z.L.; Wang, Z.Y.; Liu, J.R. Cold-field fruit extracts exert different antioxidant and antiproliferative activities in vitro. Food Chem. 2011, 129, 402-407. [CrossRef]

49. Aaby, K.; Grimmer, S.; Holtung, L. Extraction of phenolic compounds from bilberry (Vaccinium myrtillus L.) press residue: Effects on phenolic composition and cell proliferation. LWT Food Sci. Technol. 2013, 54, 257-264. [CrossRef]

50. Kropat, C.; Betz, M.; Kulozik, U.; Leick, S.; Rehage, H.; Boettler, U.; Teller, N.; Marko, D. Effect of microformulation on the bioactivity of an anthocyanin-rich bilberry pomace extract (Vaccinium myrtillus L.) in vitro. J. Agric. Food Chem. 2013, 61, $4873-4881$. [CrossRef] [PubMed] 
51. Tumbas Šaponjac, V.; Čanadanović-Brunet, J.; Ćetković, G.; Djilas, S.; Četojević-Simin, D. Dried bilberry (Vaccinium myrtillus L.) extract fractions as antioxidants and cancer cell growth inhibitors. LWT Food Sci. Technol. 2015, 61, 615-621. [CrossRef]

52. Schantz, M.; Mohn, C.; Baum, M.; Richling, E. Antioxidative efficiency of an anthocyanin rich bilberry extract in the human colon tumor cell lines Caco-2 and HT-29. J. Berry Res. 2010, 1, 25-33. [CrossRef]

53. Brown, E.M.; Nitecki, S.; Pereira-Caro, G.; McDougall, G.J.; Stewart, D.; Rowland, I.; Crozier, A.; Gill, C.I. Comparison of in vivo and in vitro digestion on polyphenol composition in lingonberries: Potential impact on colonic health. Biofactors 2014, 40, 611-623. [CrossRef]

54. Šavikin, K.; Zdunić, G.; Janković, T.; Godevac, D.; Stanojković, T.; Pljevljakušić, D. Berry fruit teas: Phenolic composition and cytotoxic activity. Food Res. Int. 2014, 62, 677-683. [CrossRef]

55. Minker, C.; Duban, L.; Karas, D.; Jarvinen, P.; Lobstein, A.; Muller, C.D. Impact of Procyanidins from Different Berries on Caspase 8 Activation in Colon Cancer. Oxid. Med. Cell Longev. 2015, 2015, 154164. [CrossRef]

56. Borowiec, K.; Szwajgier, D.; Olejnik, A.; Kowalska, K.; Targoński, Z. Effects of a bilberry preparation on selected cell lines of the digestive system. Czech. J. Food Sci. 2016, 34, 300-305. [CrossRef]

57. Hoornstra, D.; Vesterlin, J.; Parnanen, P.; Al-Samadi, A.; Zlotogorski-Hurvitz, A.; Vered, M.; Salo, T. Fermented Lingonberry Juice Inhibits Oral Tongue Squamous Cell Carcinoma Invasion In Vitro Similarly to Curcumin. In Vivo 2018, 32, 1089-1095. [CrossRef] [PubMed] 